\title{
CLONAGEM, EXPRESSÃO E PURIFICAÇÃO DE PROTEÍNAS CANDIDATAS VACINAIS DE LEPTOSPIRA INTERROGANS SOROVAR COPENHAGENI. AVALIAÇÃO DE ATIVIDADES IMUNOGÊNICAS E CARACTERÍSTICAS FUNCIONAIS
}

Dissertação apresentada ao Programa de Pós-Graduação Interunidades em Biotecnologia USP/Instituto Butantan/ IPT, para obtenção do Título de Mestre em Biotecnologia.

Área de Concentração: Biotecnologia

Orientador:

Dr. Alexandre Paulo Yague Lopes

Co-Orientador:

Dra. Elizabeth Angélica Leme Martins

São Paulo

2009 


\section{RESUMO}

LOPES, L. M. Clonagem, expressão e purificação de proteínas candidatas vacinais de Leptospira interrogans sorovar Copenhageni. Avaliação de atividades imunogênicas e características funcionais. 2009. 92 f. Dissertação (Mestrado em Biotecnologia) - Instituto de Ciências Biomédicas, Universidade de São Paulo, São Paulo, 2009.

A leptospirose é uma zoonose de distribuição mundial, causada pela bactéria espiroqueta aeróbia do gênero Leptospira. A forma grave da leptospirose é denominada doença de Weil. A leptospira é eliminada na urina de animais, sendo o rato de esgoto (Rattus novergicus) o principal reservatório para a infecção em humanos. A gravidade e freqüência da doença impõem a necessidade de desenvolvimento de uma vacina de subunidade, de baixo custo, eficaz e que determine memória imune para uso em humanos. Propusemos a investigação de 4 antígenos, VapB, VapC, Sph2 e uma proteína de camada S, cujos genes LIC12659, LIC12660, LIC12631 e LIC10868, foram clonados para expressão em E. coli e em salmonela SL3261. Estas proteínas são potencialmente relacionadas à virulência e à interação patógeno-hospedeiro, participando em mecanismos de invasão e adesão. A proteína VapC (proteína associada a virulência C) é uma toxina, cuja atividade ribonuclease foi descrita para a proteína homóloga de Haemophilus influenza. VapC tem seu efeito neutralizado pela VapB (proteína associada a virulência B) que é uma antitoxina. O par de proteínas $\mathrm{VapB}$ e VapC possui homólogos em diversas bactérias e os genes codificadores são organizados em um operon, denominado vapBC. A proteína Sph2 apresenta homologia com hemolisina e esfingomielinase. A quarta proteína é homologa a proteínas de camada $S$, associada à integridade da estrutura da superfície da bactéria. Os genes foram amplificados por PCR sobre o DNA genômico da Leptospira interrogans sorovar Copenhageni, clonados nos vetores de expressão pAE e pAEsox. As proteínas, VapB, VapC, VapBC e Sph2 foram expressas em E. coli BL21 (DE3) Star pLysS. As proteínas recombinantes foram purificadas por cromatografia de afinidade a metal. A expressão das proteínas VapB, VapC e VapBC também foi obtida em salmonela in vitro.As atividades hemolítica de Sph2 e ribonucleásica de VapC não foram evidenciadas, possivelmente devido a diferenças estruturais entre as proteínas recombinantes e as nativas. No entanto, os clones de $E$. coli contendo os genes relacionados ao módulo toxina-antitoxina - vapBC sofreram os efeitos de inibição de crescimento (vapC) e recuperação do mesmo (vapBC) previamente descritos. As proteínas recombinantes utilizadas nos ensaios imunológicos, VapB e Sph2, mostraram-se imunogênicas em camundongos e hamsters. A proteína VapB apresentada ao sistema imune como salmonela recombinante também induziu resposta imune em hamsters. Ensaios de Western Blot confirmaram o reconhecimento das proteínas recombinantes por anticorpos dos soros dos animais imunizados. A imunização com Salmonela-VapB determinou a maior imunidade protetora no teste de desafio ( $30 \%$ de sobrevivência).

Palavras-chave: Leptospira. Leptospirose. Clonagem, expressão e purificação de proteínas recombinantes. Vacinologia reversa. Salmonela vacinal. 


\section{ABSTRACT}

LOPES, L. M. Cloning, expression and purification of proteins, vaccine candidates from Leptospira interrogans sorovar Copenhageni. Evaluation of immunogenic and functional characteristics. 2009. 92 p. Master thesis (Biotechnology) - Instituto de Ciências Biomédicas, Universidade de São Paulo, São Paulo, 2009.

Leptospirosis is a zoonosis worldwide distributed, caused by the aerobic bacteria spirochaeta, genus Leptospira. The severe form of the disease is named Weil's disease. The leptospira is eliminated in the urine of animals, being the sewer rat (Rattus novergicus) the main reservoir for human infection. The severity and frequency of the disease impose the need for the development of an efficient vaccine of sub-unities, at low costs, which determines long term immune response for human uses. We proposed the investigation of 4 antigens, VapB, VapC, Sph2 and a Slayer protein, which the genes LIC12659, LIC12660, LIC12631 and LIC10868, were cloned for expression in E. coli and in salmonella SL3261. These proteins are considered potentially related to the virulence of the pathogen by participation on host/pathogen interactions, invasion and adhesion mechanisms. The protein VapC (virulence associated protein C) is a toxin. Ribonuclease activity was described for the VapC homolog in Haemophilus influenza. VapC has its effect neutralized by VapB (virulence associated protein B) an antitoxin. The pair of proteins VapB and VapC posses homologs in many other bactéria, with the coding genes organized in an operon named vapBC. The protein Sph2 is homolog to other hemolysins and sphingonyelinases. The fourth protein is homolog to proteins from S-layer, associated to the integrity of the structure of the cell surface. The genes were amplified by PCR using genomic DNA from Leptospira interrogans sorovar Copenhageni as template and cloned into expression vectors pAE e pAEsox. The proteins VapB, VapC, VapBC and Sph2 were expressed in E. coli BL21 (DE3) Star pLysS for protein purification by metal affinity chromatography. The expression of the proteins $\mathrm{VapB}, \mathrm{VapC}$ and $\mathrm{VapBC}$ were also obtained in salmonella in vitro. The hemolytic activity of Sph2 and the ribonuclease activity of VapC could not be confirmed, probably due to the differences on the structures of native and recombinant proteins. The E. coli clones with the genes related to toxin-antitoxin module - vapBC - suffered the effects of growth inhibition $(\operatorname{vap} C)$ and recovery of growth $(\operatorname{vap} B C)$ previously described. The recombinant proteins VapB and Sph2 showed to be immunogenic in mice and in hamsters. The protein VapB presented to the immune system of hamsters carried by salmonella also induced immune response. Western blot assays confirmed the recognition of the recombinant proteins by the antibodies in the sera of immunized animals. The immunization with Salmonella-VapB determined the major protective immunity on challenge assays (30\% survival).

Key words: Leptospira. Leptospirosis. Cloning, expression and purification of recombinant proteins. Reverse vaccinology. Vaccine salmonella. 


\section{INTRODUÇÃO}

\subsection{Leptospirose e leptospiras}

A leptospirose é uma zoonose de distribuição mundial com maior prevalência em países tropicais e subtropicais. Nos países desenvolvidos, a leptospirose está geralmente associada a atividades de recreação, ao passo que no Brasil e em outros países em desenvolvimento está associada com o rápido crescimento populacional, aumento de favelas, enchentes e a falta de saneamento básico. Estas condições favorecem a proliferação de roedores, vetores importantes de transmissão da leptospirose, principalmente em áreas urbanas (KO et al., 1999; LOMAR et al., 2000; PLANK e DEAN, 2000; BHARTI et al., 2003; GAMBERINI et al., 2005). A leptospirose é considerada também uma doença ocupacional, pois atinge trabalhadores de serviços de água e esgotos, canaviais, arrozais, bebedouros, tratadores de animais, veterinários, militares, dentre outros (SAKATA et al., 1992; PLANK e DEAN, 2000; BHARTI et al., 2003). A leptospirose representa um problema econômico para o Sistema de Saúde Público, pois o tratamento requer hospitalização e cerca de 15\% dos pacientes vão a óbito (KO et al., 1999).

A leptospirose humana é uma doença de notificação compulsória no Brasil. De 1985 a 2005 foram notificados 60.753 casos e 6.778 óbitos segundo o Sistema de Vigilância Epidemiológica. Os casos notificados à FUNASA/MS devem ser 10 a 20 vezes menor que a ocorrência, uma vez que as infecções são, em sua maioria, erroneamente diagnosticadas e não notificadas, (NICODEMO et al., 1997; MAROTO et al., 1997). Só no estado de São Paulo, no ano de 2006, ocorreram 1060 casos e 132 óbitos (Centro de Zoonoses - Centro de Vigilância Epidemiológica).

Recentemente, no final de novembro passado, nos vinte e seis dos 47 municípios atingidos pelas chuvas que castigaram o estado de Santa Catarina, foram registrados 301 casos de leptospirose confirmados pela Vigilância Epidemiológica da Secretaria de Estado da Saúde de Santa Catarina.

A leptospirose foi primeiramente descrita em 1886 por Adolf Weil. O agente etiológico da doença são espiroquetas patogênicas, pertencentes à Ordem Spirochaetales, Família Leptospiraceae e Gênero Leptospira. São microrganismos aeróbios obrigatórios, helicoidais, flexíveis e móveis que medem de 6 a $20 \mu \mathrm{m}$ de comprimento e 0,1 $\mu \mathrm{m}$ de diâmetro. Apresentam as extremidades dobradas ou em 
forma de ganchos e são constituídas por um corpo citoplasmático e filamento axial enrolados em espiral, sendo ambos envolvidos por uma membrana denominada envelope ou membrana envolvente. O citoplasma é envolvido por uma membrana citoplasmática e uma camada de peptidoglicano formando um complexo. O complexo basal destes flagelos é semelhante ao de uma bactéria Gram-negativa, contudo com baixa atividade endotóxica (TRABULSI, 1996; PLANK e DEAN, 2000; VERONESI, 2004; CORRÊA, 2005).

Primeiramente o gênero Leptospira foi dividido em duas espécies pela classificação fenotípica: L. biflexa (sorovares saprófitos, de vida livre) e $L$. interrogans (sorovares patogênicos) (LEVETT, 2001). Atualmente a classificação genotípica identifica 17 espécies de Leptospira: L. interrogans, L. biflexa, $L$. alexandrei, L.alexandrei, L. fainei, L. borgpetersenii, L. santarosai, L. inadai, L. noguchii, L. weilii, L. kirshneri, L. meyeri, L. wolbachii, e as geno-espécies 1, 2, 3, $4 \mathrm{e}$ 5, ainda sem denominação (BHARTI et al., 2003). Elas também são classificadas de acordo com o sorovar, o que está relacionado com anticorpos específicos determinados pela variação na porção e tipos de carboidrato do lipopolisacarideos (LPS). Existem mais de 226 sorovares nos 24 sorogrupos fenotipicamente agrupados como L. interrogans e 65 sorovares agrupados em 38 sorogrupos fenotipicamente agrupados como L. biflexa (FARR, 1994; FAINE et al., 1999; PLANK e DEAN, 2000; LEVETT, 2001; BHARTI et al., 2003; NASCIMENTO et al., 2004; GAMBERINI et al., 2005; VERONESI, 2004; CORRÊA, 2005).

A Leptospira interrogans (fig.1) abrange todos os sorotipos associados a infecções humanas e animais (TRABULSI, 1996), atingindo animais domésticos (cães, gatos) e outros de importância econômica (bois, cavalos, porcos, cabras, ovelhas) (PLANK e DEAN, 2000; BHARTI et al., 2003; NASCIMENTO et al., 2004). Os variantes da bactéria não possuem especificidade por determinados hospedeiros, mas possuem certas preferências. Por exemplo, o sorogrupo Icterohaemorrhagiae é o mais importante em termos de saúde pública já o sorogrupo Pomona tem tropismo pelos suínos e o Hardjo, por bovinos. O sorogrupo Icterohaemorrhagiae tem como hospedeiro preferencial o rato de esgoto (Rattus norvegicus), considerado o principal transmissor da leptospirose para o homem, pela proximidade e por existir em grande número. Os roedores das espécies Rattus rattus (rato de telhado ou rato preto) e Mus musculus (camundongo ou catita) também 
podem desempenhar o papel de transmissor (Coordenação de vigilância em saúde COVISA-SP; NASCIMENTO et al., 2004).

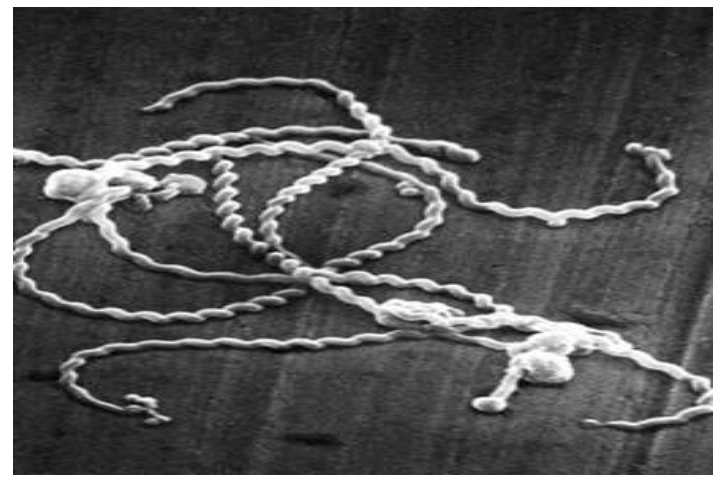

FIGURA 1- Microscopia eletrônica de varredura de Leptospira interrogans.

A L. interrogans sorovar Copenhageni e L. interrogans sorovar Icterohaemorrhagiae são os principais agentes etiológicos dos casos de leptospirose em humanos no Brasil, onde a incidência da doença é maior no período de janeiro a abril; sendo o sorovar Copenhageni mais comum nas regiões Sudeste e Nordeste do país (VERONESI, 2004; CORRÊA, 2005).

A imunidade à infecção inicial por leptospiras é dependente basicamente de resposta humoral, majoritariamente contra os LPSs (ADLER e FAINE, 1978). A opsonização das bactérias permite que sejam fagocitadas e eliminadas da corrente sangüínea no começo da infecção (FAINE et al., 1964). Indivíduos que contraem leptospirose ficam protegidos contra a reinfecção pelo mesmo sorovar ou por sorovares relacionados por certo período de tempo (LEVETT, 2001).

Roedores peridomiciliares e silvestres são portadores naturais de leptospiras com ampla dispersão geográfica. Animais domésticos, principalmente os bovinos, suínos e cães são importantes na cadeia epidemiológica e podem ser portadores de determinados sorovares por períodos prolongados. Nos portadores naturais a infecção é crônica com colonização da bactéria nos túbulos renais e eliminação intermitente através da urina, sem evidências de alterações patológicas. As interações da espiroqueta com os hospedeiros constituem processos dinâmicos, sendo que os hospedeiros podem ser suscetíveis a determinados sorovares e refratários a outros (CORRÊA, 2005).

A L. interrogans multiplica-se nos rins dos animais portadores sem causar danos. A bactéria é eliminada pela urina, às vezes por toda a vida do animal, e sobrevive no solo úmido ou na água. $\mathrm{O}$ homem é infectado casual e 
transitoriamente, e não tem importância como transmissor da doença. A transmissão de uma pessoa para outra é muito pouco provável (MURRAY et al., 2000; PLANK e DEAN, 2000; BHARTI et al., 2003).

A transmissão ao homem pode ocorrer por contato direto com sangue, tecidos, órgãos ou urina de animais infectados, ou, por via indireta, através do contato com água, lama das enchentes ou solo contaminado com a urina dos animais portadores. Também pode ocorrer a transmissão acidental em laboratório, por mordedura de ratos e pela via transplacentária que é rara em humano e comum em animais (VERONESI, 2004).

Após penetrar pela mucosa ou pele, as bactérias disseminam-se rapidamente pela circulação sanguínea para todos os tecidos, incluindo o sistema nervoso central e os olhos, porém, com localização especial em determinados órgãos, particularmente fígados, rins, coração e músculo esquelético. A bactéria multiplicase rapidamente e provoca lesão no endotélio vascular, a que é responsável pelas principais manifestações clínicas da doença (intensa vasculite). Os microrganismos, no estágio inicial da doença, podem ser encontrado no sangue (fase leptospirêmica) e líquido cefalorraquidiano e, nas fases mais avançadas, na urina (fase imune ou leptospúrica) (MURRAY et al., 2000; PLANK e DEAN, 2000; BROD et al., 2005).

As leptospiras são microrganismos que usam ácidos graxos como fonte de energia e aderem à membrana celular, o que pode ser interpretado como um passo inicial importante no estabelecimento da infecção (VERONESI, 2004).

A manifestação clínica da leptospirose é facilmente confundida com os sintomas de outras doenças, como a gripe e a dengue. As manifestações iniciais são febre alta de início súbito, sensação de mal estar, dor de cabeça constante e acentuada, dor muscular intensa (principalmente na panturrilha), cansaço, calafrios e é caracterizada por intensa vasculite. Dor abdominal, náuseas, vômitos e diarréia são freqüentes, podendo levar à desidratação. É comum que os olhos fiquem acentuadamente avermelhados (hiperemia conjuntival) e que alguns doentes apresentem tosse e faringite. Após dois ou três dias de aparente melhora, os sintomas podem ressurgir, ainda que menos intensamente. Nesta fase é comum o aparecimento de manchas avermelhadas no corpo (exantema) e pode ocorrer meningite, que em geral tem boa evolução (PLANK e DEAN, 2000; BHARTI et al., 2003; NASCIMENTO et al., 2004). 
Em cerca de $10 \%$ dos pacientes, a partir do terceiro dia de doença surge icterícia intensa (olhos amarelados), o que caracteriza os casos mais graves. Esses casos são mais comuns (90\%) em adultos jovens do sexo masculino e raro em crianças. Aparecem manifestações hemorrágicas (equimoses, sangramentos em nariz, gengivas e pulmões) e pode ocorrer funcionamento inadequado dos rins, o que causa diminuição do volume urinário e, às vezes, anúria total. A forma grave da leptospirose é denominada doença de Weil. A evolução para a morte pode ocorrer em cerca de $10 \%$ a $15 \%$ dos pacientes com formas graves da doença (MURRAY et al., 2000; PLANK e DEAN, 2000; LEVETT, 2001; NASCIMENTO et al., 2004; GAMBERINI et al., 2005). A forma grave da leptospirose é comumente associada ao sorogrupo Icterohaemorrhagie (BHARTI et al., 2003).

Para o diagnóstico da leptospirose, testes sorológicos são os mais comumente empregados. Um teste elaborado como referência pela Organização Mundial da Saúde é o teste de Microaglutinação (MAT). (LEVETT, 2003; SÃO PAULO, 1994; BROD et al., 2005). Testes para detecção de IgM específica por reação de ELISA são feitos após 7 dias do início da doença. Se o exame der negativo, deve ser colhida amostra novamente após 7 dias (SÃO PAULO, 1994). Métodos moleculares estão sendo desenvolvidos, principalmente baseados primers específicos para PCR e análises de restrição (HEINEMANN et al., 2000; LEVETT, 2001).

O tratamento da leptospirose é feito com Penicilina G cristalina e como alternativas, a Ampicilina, Tetraciclina ou Doxiciclina (MURRAY et al., 2000). A terapia de suporte é importante para tratar sintomas como desidratação, febre, hipotensão, falência renal e hemorragia (KO et al., 1999).

Na profilaxia da leptospirose o importante é impedir que o homem sadio entre em contato com águas ou animais contaminados, assim como a imunização dos animais domésticos e animais de rebanho.

\subsection{Vacinas}

Vacinas obtidas a partir de preparações de leptospira atenuada/inativada (bacterina), para uso veterinário, estão no mercado, porém sua capacidade imunogênica é baixa e não induz resposta imunológica contra outros sorovares 
(FAINE et al., 1999). Há relatos de animais que apresentam leptospirúria após a vacinação (PLANK e DEAN, 2000).

A gravidade e freqüência da doença impõem à necessidade de desenvolvimento de uma vacina licenciada para uso humano. Atualmente existem vacinas humanas disponíveis, baseadas em preparações de leptospiras atenuada/inativadas (Cuba e Japão), ou baseadas em preparações da membrana externa (China). Tais vacinas são licenciadas somente nos países em que foram desenvolvidas.

Vários trabalhos têm sido publicados sobre o desenvolvimento de vacinas humanas contra a leptospirose. Entretanto, os resultados também são controversos. As vacinas testadas são produzidas a partir de culturas de diferentes sorovares de $L$. interrogans, e as culturas mortas pela ação do calor e/ou formol. Zhuo e colaboradores (1995) testaram uma vacina em área endêmica na China e observaram que crianças abaixo de 14 anos não estavam protegidas contra a doença. As vacinas obtidas a partir de bactérias inativadas ou atenuadas promovem imunidade timo-independente, com desvantagem de não induzir memória imunológica, alem de serem impuras e reatogênicas, pois contêm contaminantes indesejáveis oriundos do próprio processo de obtenção. Nesse tipo de vacina, as bacterinas, a resposta imune primária contra os açúcares dos lipopolisacarídeos (LPS) da superfície das Leptospira que determinam a especificidade de sorogrupos e sorovares (BHARTHI et al., 2003, FAINE et al., 1999).

A variedade de sorovares em regiões distintas dificulta a obtenção de uma vacina única para prevenir a doença em humanos, o que conseqüentemente reduz o interesse comercial no desenvolvimento.

Atualmente, se busca é uma vacina de componente(s) bem definido(s) e sem contaminações, que induza resposta imunológica timo-dependente, com mínimos efeitos adversos e baixo custo. Com este objetivo, o genoma da espiroqueta Leptospira interrogans sorovar Copenhageni foi seqüenciado pelo Consórcio AEGAgronomical \& Environmental Genomes/ONSA/FAPESP, sob a coordenação geral da Dra. Ana Lúcia Tabet Oller do Nascimento (Centro de Biotecnologia do Instituto Butantan) (NASCIMENTO et al., 2004).

A partir de investigações sobre o genoma da bactéria, um projeto temático para desenvolvimento de vacinas foi proposto "Clonagem e expressão de candidatos vacinais contra a leptospirose identificados no projeto genoma Leptospira 
interrogans sorovar Copenhageni”, sob coordenação do Dr. Paulo Lee Ho do Instituto Butantan, sendo o trabalho aqui descrito, parte desse projeto temático.

\subsection{Genoma da Leptospira interrogans sorovar Copenhageni}

Até o momento foram seqüenciados cinco genomas de linhagens de leptospiras: Leptospira interrogans sorovar Lai (REN et al., 2003); Leptospira interrogans sorovar Copenhageni (NASCIMENTO et al., 2004); duas linhagens de Leptospira borgpetersenii sorovar Hardjo (BULACH et al., 2006) e mais recentemente o genoma da leptospira de vida livre Leptospira biflexa sorovar Patoc (PICARDEAU, 2008).

O genoma da Leptospira interrogans sorovar Copenhageni seqüenciado pertence a linhagem Fiocruz L1-130 que foi isolada de um paciente com leptospirose severa durante um surto epidêmico em Salvador (BA) ocorrido em 1996 pelo grupo do Dr. Albert Ko (Fiocruz - BA) (KO et al., 1999). O isolado foi identificado e o DNA genômico extraído para o seqüenciamento pelo Consórcio descrito acima.

As duas espécies patogênicas para humanos, Copenhageni e Lai, possuem dois cromossomos, um maior (4,3 a 3,6 Mpb) e outro menor (358 a $316 \mathrm{~kb}$ ) codificando cerca de 3700 genes. Na espécie de vida livre é observado, além dos dois cromossomos semelhantes ao das espécies patogênicas, uma terceira unidade de replicação de cerca de $74 \mathrm{~kb}$. O genoma de leptospiras pode ser considerado grande quando comparado ao de outras espiroquetas, o que pode estar relacionado à habilidade da Leptospira spp de viver em diferentes condições, como no hospedeiro animal e livre no meio ambiente (BHARTI et al., 2003).

Foram identificadas diversas proteínas a partir do seqüenciamento do genoma da $L$. interrogans sorovar Copenhageni considerados potenciais antígenos vacinais, com estruturas sugestivas de interação com o hospedeiro, ou atividades relacionadas com a patogênese (GAMBERINI et al., 2005). Alguns genes associados com a patogênese estão indicados na tabela I. 
TABELA 1 - Genes de L. interrogans sorovar Copenhageni possivelmente envolvidos na patogênese da bactéria.

\begin{tabular}{ll}
\hline Candidato & № de genes \\
\hline LPS & 23 \\
Mobilidade e quimiotaxia & 73 \\
Proteínas de adesão e superfície & \\
- Adesinas afimbriais - domínio similar à imunoglobulina & 3 \\
$\quad$ - domínios repetidos de FG-GAP & 3 \\
- Proteínas similares à hemaglutininas & 9 \\
- Lipoproteínas & 174 \\
- Polissacarídeos capsulares / exopolissacarídeos secretados & 33 \\
Degradação da membrana celular do hospedeiro & \\
- Hemolisina similar à esfingomielinase C & 5 \\
- Homólogo da fosfolipase D & 1 \\
- Hemolisina (homólogos - tlyABC) & 3 \\
Proteases & \\
- Colagenase & 1 \\
- Metaloproteinase & 1 \\
- Termolisina & 1 \\
Proteínas similares à ankirina & 12 \\
Resistência ao estresse oxidativo & 8 \\
\hline
\end{tabular}

A resposta adaptativa da leptospira ao seu ambiente deve envolver uma rede complexa de sinalização, como é sugerido pelo número de genes (79) codificando proteínas com função regulatória e de transdução de sinal. Também ocorre um grande número de genes (79) envolvidos com motilidade celular e quimiotaxia, o que deve refletir a sua habilidade de responder à diversidade de estímulos ambientais, inclusive a capacidade de localização e penetração no hospedeiro e a posterior distribuição nos órgão, ainda que não exista uma evidência direta que motilidade e quimiotaxia estejam envolvidos na entrada no hospedeiro (FAINE et al., 1999). A disseminação da leptospira aos órgãos deve ser facilitada por enzimas como esfingomielinase $C$ e pela fosfolipase $D$. A ação hemolítica também pode ser mediada por hemolisinas do tipo tlyABC, semelhante as observadas em Serpulina 
hyodysenteriae. Colagenases, metaloprotease e termolisina foram identificadas como sendo lipoproteínas e devem estar relacionadas à invasão e patogenicidade destas bactérias. Fatores de colonização também devem participar na disseminação da leptospira nos órgãos do hospedeiro. Foram encontradas adesinas, algumas com estruturas repetitivas de imunoglobulinas e outras com estrutura de integrinas. Um grande número de genes relacionados à biosíntese de polissacarídeos capsulares foram evidenciados e outros sugerindo a possibilidade de leptospiras formar biofilmes durante a infecção. Também foram identificadas 174 lipoproteínas de superfície, o que as caracterizam como candidatos potenciais para antígenos vacinais e diagnósticos (NASCIMENTO et al., 2004).

\subsection{Genes de L. interrogans sorovar Copenhageni selecionadas para investigação neste projeto}

A tabela 2 mostra os genes escolhidos após análise do genoma para desenvolvimento deste projeto.

TABELA 2 - Genes de L. interrogans svr Copenhageni selecionados para estudo.

\begin{tabular}{cccc}
\hline Gene & Similaridade & $\begin{array}{c}\text { Número de pares } \\
\text { de bases }\end{array}$ & $\begin{array}{c}\text { Número de aminoácidos da } \\
\text { proteína codificada }\end{array}$ \\
\hline LIC12659 & $\begin{array}{c}\text { VapB- proteína } \\
\text { associada à virulência } \\
\text { VapC- proteína } \\
\text { LIC12660 }\end{array}$ & 231 & 77 \\
associada à virulência \\
LIC12631 & $\begin{array}{c}\text { Sph2- Hemolisina/ } \\
\text { esfingomielinase } \\
\text { Proteína associada à } \\
\text { LIC10868 }\end{array}$ & 1872 & 624 \\
\hline
\end{tabular}

As seqüências dos genes utilizados neste projeto estão depositadas no banco público de dados NCBI (http://www.ncbi.nlm.nih.gov/) e na página oficial do genoma da L. interrogans sorovar Copenhageni (http://aeg.lbi.ic.unicamp.br/world/lic/). 
Os 4 genes LIC12659, 12660, 12631 e 10868 codificam proteínas potencialmente relacionadas com virulência e com a interação patógeno-hospedeiro, como mecanismos de invasão e adesão.

O gene LIC 12659 codifica uma proteína identificada por Blast ("BLAST" "Basic Local Alignment Search Tool") como homologa a VapB - "virulence associated protein B" - descrita inicialmente em Dichelobacter nodosus e assim denominada por ter sido encontrada nos genomas de todos os isolados patogênicos, desta bactéria, causadora de footrot em ovinos (KATZ, 1991).

O gene LIC12660 codifica a proteína homologa a VapC - "virulence associated protein C". A proteína VapC apresenta domínios PIN (supostamente relacionados com atividades ribonucleásicas, presentes em uma grande família de proteínas de eucariotos e procariotos (COOPER et al., 2009). A maioria das proteínas que possuem este domínio são tóxicas (ARCUS et al., 2005, BUNKER et al., 2008). A proteína VapC é uma toxina, cuja atividade ribonuclease foi descrita para a proteína homóloga de Haemophilus influenza e tem seu efeito neutralizado pela VapB que é uma antitoxina (DAINES et al., 2007).

O gene LIC12631 codifica uma hemolisina com 56\% de similaridade com esfingomielinase de Pseudomonas sp. Foi classificada na categoria primária de "patogênicidade, virulência, adaptação, produção de toxina e detoxificação". O programa PSORT indica que é uma proteína localizada na membrana interna da bactéria (http://aeg.lbi.ic.unicamp.br/world/lic/).

A LIC10868 mostrou-se homologia com proteínas associadas à camada S (Slayer), que fornecem integridade na estrutura da superfície da bactéria, embora este tipo de proteína não tenha sido observada em leptospiras patogênicas, o genoma contém pelo menos 2 proteínas de camada S, LIC10868 e LIC 12952 (NASCIMENTO et al., 2004).

\subsubsection{Complexo toxina-antitoxina (locus vapBC)}

Genomas de bactérias freqüentemente contêm vários loci toxina-antitoxina (TA). Eles são organizados em operons que codificam duas proteínas, a primeira, uma antitoxina, que neutraliza a segunda, uma toxina. Os módulos TA são divididos em 7 famílias de genes (relBE, parDE, higBA, vapBC, mazEF, phD-doc e ccdAB) e foram primeiramente encontrados em plasmídeos, principalmente em archaeas e 
bactérias patogênicas e, por este motivo, foram relacionados com a virulência da bactéria. A família vapBC é a família mais abundante, representando cerca de $40 \%$ dos TA encontrados em bactérias Gram negativa, Gram positiva e também em archaea (BODOGAl et al., 2008; COOPER et al., 2009). De acordo com análise genômica comparativa in silico, as seqüências LIC12659 e LIC12660 formam um operon denominado vapBC. O módulo VapBC foi descrito em Leptospira interrogans serovar Lai e a expressão da VapC em Escherichia coli resultou na inibição do crescimento bacteriano, enquanto a co-expressão de VapC e VapB restaurou o crescimento (ZHANG et al., 2004). De acordo com Daines e colaboradores (2007), a proteína VapC de Haemophilus influenza é uma toxina, com atividade ribonuclease, que tem seu efeito neutralizado pela $\mathrm{VapB}$, a antitoxina.

Os módulos TA parecem possuir um importante papel dentro da fisiologia do estresse bacteriano. Em experiências laboratoriais foi evidenciado que os módulos TA proporcionam um mecanismo que ajuda as células a sobreviverem em condições de crescimento desfavoráveis em resposta ao estresse. Em condições normais a antitoxina inibe a toxina e o complexo TA age como um repressor sobre o operon TA, enquanto que, em condições de ativação, a velocidade de degradação proteolítica da antitoxina ultrapassa sua síntese (BUTS et al., 2005; PANDEY e GERDES, 2005; GERDES et al., 2005). Devido ao fato da antitoxina ser degradada continuamente, nova síntese é necessária para manter um elevado nível da antitoxina, que forma um complexo inibidor com a toxina. A degradação da antitoxina na ausência de nova síntese protéica leva à morte celular, uma vez que a toxina é menos vulnerável a ação proteolítica (HAYES e SAUER, 2003; BUTS et al., 2005; ARCUS et al., 2005).

Os módulos TA são ativados em condições de estresse, como a falta de aminoácidos, falta de timina, danos de DNA, presença de antibióticos ou infecção por fagos, sugerindo que os módulos TA estejam envolvidos na mediação da morte celular programada (BUTS et al., 2005; GERDES et al., 2005). A análise do trascriptoma de Sulfolobus solfataricus, que codifica pelo menos 26 loci de vapBC, sugere que o lócus tem função na resposta ao choque térmico desta archaea, pois a expressão de vários operons $v a p B C$ foi disparada quando estas bactérias foram submetidas a elevações de temperatura (COOPER et al., 2009). 


\subsubsection{Hemolisinas}

As leptopiras dependem de ferro para crescer e se multiplicar e por isso a capacidade de gerar hemólise parece ser essencial para a sobrevivência e para a reprodução das leptospiras patogênicas, uma vez que o rompimento dos eritrócitos libera uma grande quantidade de ferro (WANDERSMAN e STOJIEJKOVIC, 2000).

Em leptospiras, a hemólise é caracterizada pela atividade de esfingomielinases, fosfolipases e de outras proteínas auxiliadoras (LEE et al., 2000). As leptospiras patogênicas possuem múltiplos genes que codificam para esfingomielinases, que podem estar associadas, além da aquisição de ferro, ao uso dos lipídeos de membrana como fonte de carbono e energia e à geração de morte celular no hospedeiro (CARVALHO, 2008).

A proteína Sph2 (LIC12631) possui um domínio exo-endo-phos (exonucleaseendonuclease-fosfatase), encontrado em diversas enzimas, incluindo as esfingomielinases. As esfingomielinases são enzimas responsáveis pela geração de ceramida e fosforilcolina a partir da hidrólise da esfingomielina (um fosfolipídeo constituinte da membrana plasmática). Em procariotos não são necessárias para o ciclo de vida, mas são encontradas freqüentemente em patógenos, atuando como toxinas. Em leptospiras os genes que codificam esfingomielinases são encontrados somente em linhagens patogênicas. A proteína Sph2 é produzida somente durante a infecção e foi relatada sua habilidade em romper membranas (CARVALHO, 2008; ARTIUSHIN et al., 2004).

\subsection{Salmonelas recombinantes como carregadores de antígenos vacinais}

A salmonela é uma bactéria em forma de bastonete, Gram negativa, com características invasivas de mamíferos e com tropismo por macrófagos. Sobrevive nos fagolisossomos e utiliza mecanismos de defesa antioxidantes (TRABULSI, 1996).

Diferentes linhagens de salmonelas com patogenicidade atenuada têm sido utilizadas como vacinas vivas (GARMORY et al., 2002). As bactérias atenuadas permanecem nos hospedeiros por tempo suficiente para estimular o sistema imune (ROSENKRANZ et al., 2003). Antígenos de diversos patógenos, bacterianos, 
protozoários e virais têm sido clonados em salmonela de maneira a induzir resposta imune nos hospedeiros (GARMORY et al., 2002).

Existem diferentes linhagens mutantes de salmonelas desenvolvidas para utilização como vetores vacinais vivos. As linhagens mais importantes foram obtidas pela deleção dos genes aro, tornando as bactérias nutricionalmente dependentes de precursores aromáticos para síntese de aminoácidos aromáticos e vitaminas, limitando sua sobrevivência no tecido infectado e assim atenuando acentuadamente sua patogenicidade (CHATFIELD E DOUGAN, 1997; COYNAULT e NOREL, 1999).

A infecção natural por salmonelas se da por via de mucosas (SIRARD et al., 1999) e segue-se infecção sistêmica. Primariamente ocorre uma resposta imune para mucosas e então as respostas humoral e celular. Têm sido descritas manipulações genéticas com o fim de se obter proteínas quiméricas que direcionariam os antígenos no sistema imune dos hospedeiros de forma a modular as respostas segundo o tipo que se deseja priorizar (CHEN e SCHIFFERLI, 2000). Outro aspecto investigado é a capacidade das salmonelas atuarem como adjuvantes vacinais, dirigindo a resposta imune através de células Th1 (JÖRG LEHMANN et al., 2006), além da resposta humoral mediada por células Th2 e da resposta secretora $(\lg A)$. Além disto, demonstrou-se que diferentes respostas imunes são determinadas pela via de imunização utilizada, nasal, oral, intraperitonial, subcutânea ou endovenosa (SBROGIO-ALMEIDA e FERREIRA, 2001; TOMITA, 2005).

Foi demonstrado que salmonela é também um bom veículo para transferência de informação genética para expressão de proteínas sob controle da maquinaria de replicação e tradução das células do hospedeiro. Verificou-se que essas proteínas podem estimular o sistema imune, confirmando que salmonelas recombinantes representam uma ferramenta bastante versátil para o desenvolvimento de vacinas. Elas apresentam a vantagem de imunização direta, dispensando etapas de purificação e renaturação de proteínas, reduzindo assim o custo das vacinas. A clonagem em salmonelas possibilita a expressão dos antígenos na forma nativa e a apresentação direta ao hospedeiro (TOMITA, 2005).

Escolhemos para estudos de sistemas de expressão a linhagem de $S$. entérica sorovar Typhimurium SL3261, a qual possui uma deleção do gene aroA, sendo dependente do substrato ácido p-aminobenzóico (PABA) ou aminoácidos aromáticos para sobrevivência e por isso tendo crescimento limitado nos tecidos 
infectados onde os substratos são pouco disponíveis (HOISETH e STOCKER, 1981).

\subsubsection{Regulon soxRS}

Existem muitos dados sobre a utilização de promotores de expressão gênica ativados in vivo, ou seja, induzidos por características específicas do micro-ambiente do hospedeiro com possibilidade de uso em salmonela. Vários estudos descritos na literatura demonstram as características do regulon sox $R S$, o qual é ativado em $E$. coli em resposta ao estresse oxidativo que ocorre durante infecção nos hospedeiros mamíferos (DEMPLE, 1996). O regulon é comprovadamente induzido em macrófagos por radicais superóxido e oxido nítrico. O controle de expressão do regulon é feito em dois estágios, com uma proteína sensora de estresse oxidativo, SoxR, a qual ativada, atua sobre o promotor do gene soxS (fator de transcrição), induzindo forte expressão. A proteína SoxS vai então ativar a expressão de ao menos quinze genes relacionados com a defesa contra estresse oxidativo, como superoxido dismutase A, aconitase, glicose-6-fosfato desidrogenase, fumarase C, endonuclease IV. Foi demonstrado a existência do controle desse regulon em salmonela e em outras enterobactérias (TOMITA, 2005; KOUTSOLIOUTSOU et al., 2001). Verificou-se que mutações específicas no gene de sox $R$ podem acarretar alteração conformacional da proteína SoxR de modo a manter a expressão de soxS constitutiva. De fato, essa mutação em sox $R$ foi verificada em salmonela resistente a antibióticos, isolada de paciente após reincidência de salmonelose. A mutação foi transferida a outras cepas de salmonelas conferindo características de resistência a antibióticos e expressão constitutiva das proteínas do regulon soxRS (KOUTSOLIOUTSOU et al., 2001).

Estudos com o sistema soxR-promotor-soxS no controle da expressão de fragmento $C$ de toxina tetânica mostram resultados interessantes em termos de ativação do sistema imune de camundongos A linhagem recombinante de $S$. typhimurium SL3261 foi capaz de proteger os camundongos desafiados com a toxina tetânica após duas doses administradas pela via oral (TOMITA, 2005). 


\subsubsection{Vetor pAEsox}

Foi desenvolvido em nosso laboratório um vetor de expressão denominado pAEsox que utiliza o sistema soxR/soxS para controlar a expressão de genes de interesse. $O$ vetor $P A E$ foi construído no Centro de Biotecnologia a partir dos vetores comerciais pRSET e pET (Ramos et al., 2004), para expressão de proteínas em $E$. coli, por indução com isopropil $\beta$-d-tiogalactosídeo (IPTG). O pAE foi modificado neste laboratório por inserção do sistema controlador do regulon soxRS, o gene de sox $R$ e promotor de soxS, permitindo a clonagem de genes de interesse posicionados substituindo o gene soxS, de maneira que a expressão desses genes ficasse sob controle do promotor de soxS, e portanto induzidos por SoxR em caso de estresse oxidativo. O sistema soxRS pode ser ativado in vitro por exposição das bactérias a Paraquat $(\mathrm{PQ})$, uma bipiridina que promove estresse oxidativo similar ao imposto às bactérias durante a infecção (DEMPLE, 1996).

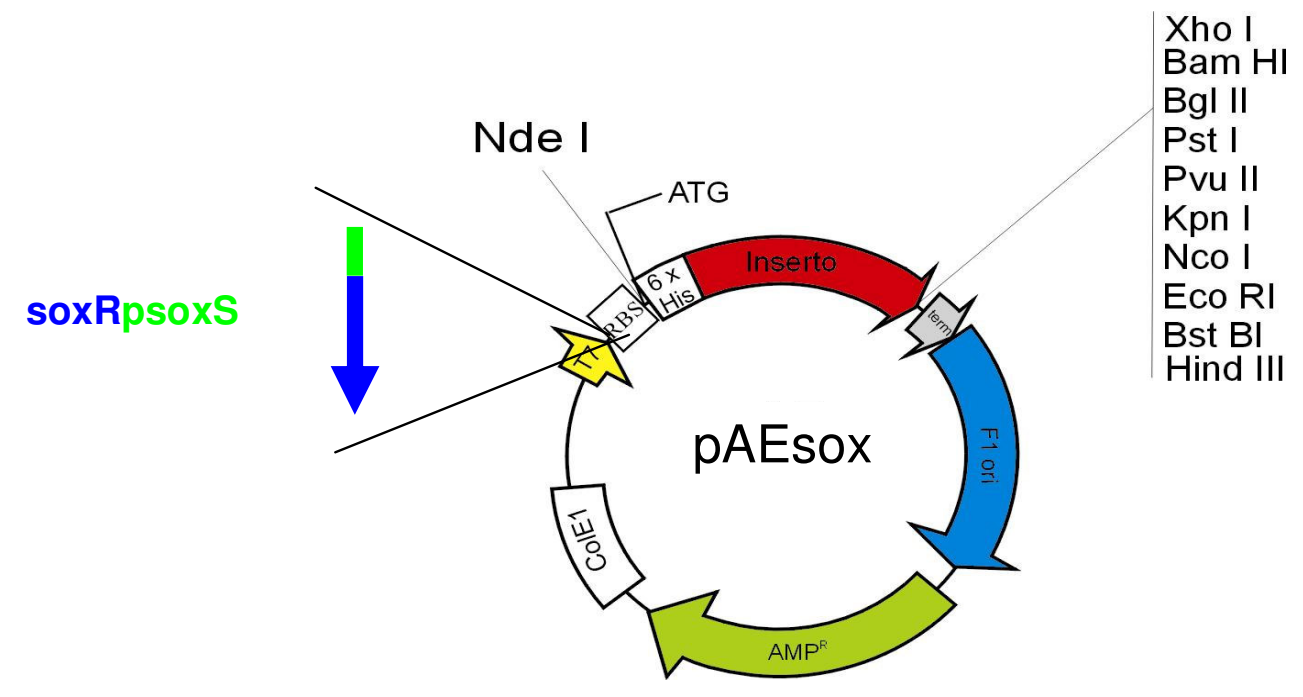

FIGURA 2- Esquema do vetor pAEsox. 


\section{CONCLUSÕES}

Este trabalho propôs a obtenção de proteínas recombinantes a partir dos genes LIC12659, LIC12660, LIC12631, e LIC10868 de Leptospira interrogans sorovar Copenhageni e a avaliação de atividades imunogênicas e características funcionais.

Todos os genes foram clonados nos vetores de expressão pAE e pAEsox e as proteínas recombinantes, com exceção da proteína codificada pelo gene LIC10868, expressas com sucesso em E. coli BL21. Em Salmonella typhimurium SL3261 obteve-se a expressão in vitro das proteínas do módulo VapBC.

As proteínas Sph2 e VapC expressas em corpúsculos de inclusão tornaramse solúveis após os processos de renaturação, no entanto, as referidas atividades enzimáticas não foram observadas.

O operon vapBC (LIC12659/12660) foi clonado em E. coli e S. typhimurium, onde foi obtida a expressão das duas proteínas de maneira similar ao que deve ocorrer na bactéria de origem do operon.

Foi demonstrado que o crescimento de $E$. coli foi inibido pela presença do vetor contendo o gene vapC e normalizado pela presença de vap $B$ no vetor que carrega o módulo $v a p B C$, provavelmente pela toxidade da proteína VapC e neutralização pela VapB.

De maneira inversa ao esperado, nossos ensaios demonstraram que a atividade ribonuclease estava presente nos preparados de VapB e do complexo copurificado $\mathrm{VapBC}$, mas não de $\mathrm{VapC}$. O uso de proteínas controle obtidas de maneira idêntica a VapB descartaram a presença de RNases contaminantes devido ao processo de purificação, sendo necessários estudos mais detalhados para confirmação deste achado.

As proteínas recombinantes VapB e Sph2 mostraram-se imunogênicas, induzindo resposta imune em camundongos e hamsters e os ensaios de Western blot indicaram o reconhecimento das proteínas recombinantes nos soros dos animais imunizados.

A imunização em hamsters com Salmonela-VapB induziu resposta imune que resultou em $30 \%$ de proteção contra o desafio por L. interrogans. 


\section{REFERÊNCIAS BIBLIOGRÁFICAS}

ARCUS,V. L.; RAINEY, P. B.; TURNER, S. J. The PIN-domain toxin-antitoxin array in mycobacteria. Trends Microbiol., v.13, n. 8, p. 258-263, 2005.

ARTIUSHIN, S.; Timoney, J. F.; Nally, J.; Verma, A. Host-inducible immunogenic sphingomyelinase-like protein, Lk73.5, of Leptospira interrogans. Infect. Immun., v. 72, n. 2, p. 742- 749, 2004.

ASHBY, D.; LEDUC, I.; LAUZON, W.; LEE, B. C.; SINGHAL, N.; CAMERON, D. W. Attenuated Salmonella typhimurium SL3261 as a vaccine vector for recombinant antigen in rabbits. J. Immunol. Methods, v. 299, p.153-164, 2005.

BHARTI, A. R.; NALLY, J. E.; RICALDI, J. N.; MATTHIAS, M. A.; DIAZ, M. M.; LOVETT, M. A.; LEVETT, P. N.; GILMAN, R. H.; WILLIG, M. R.; GOTUZZO, E.; VINETZ, J. M. Leptospirosis: a zoonotic disease of global importance. Lancet Infect. Dis., v. 3, n. 12, p. 757-771, 2003.

BROD, C. S.; ALEIXO, J. A. G.; JOUGLAR, S. D. D.; FERNANDES, C. P. H.; TEIXEIRA, J. L. R.; DELLAGOSTIN, O. A. Evidência do cão como reservatório da leptospirose humana: isolamento de um sorovar, caracterização molecular e utilização em inquérito sorológico. Rev. Soc. Bras. Med. Trop., v. 38, n. 4, p. 294300, 2005.

BODOGAI, M.; FERENCZI, S. Z.; MICLEA, S. P.; PAPP, P.; DUSHA, I. Toxinantitoxin modules and symbiosis. Curr. Plant. Sci. Biotech. Agri., v. 42, p. 237-238, 2008.

BULACH, D. M.; ZUERNER, R. L.; WILSON, P.; SEEMANN, T.; MCGRATH, A.; CULLEN, P. A.; DAVIS, J.; JOHNSON, M.; KUCZEK, E.; ALT D. P. Genome reduction in Leptospira borgpetersenii reflects limited transmission potential. Proc. Natl. Acad. Sci., v.103, n. 39, p. 14560-14565, 2006.

BUTS, L.; LAH, J.; DAO-THI, M. H.; WYNS L.; LORIS, R. Trends Biochem. Sci., v. 30, n. 12, p. 672-679, 2005.

CARVALHO, E. Análise das proteínas de Leptospira com possível papel hemolítico através de expressão recombinante: detecção de expressão nativa, atividade biológica e potencial vacinal. $100 \mathrm{f}$. Tese (Doutorado em Genética) Instituto de Biociências, Universidade de São Paulo, São Paulo, 2008.

CENTRO DE VIGILÂNCIA EPIDEMIOLÓGICA. 2006. Disponível em: <http://www.cve.saude.sp.gov.br/>. Acesso em: 8 fev. 2009.

\footnotetext{
De acordo com:

ASSOCIAÇÃO BRASILEIRA DE NORMAS TÉCNICAS. NBR 6023: Informação e documentação: referências: elaboração. Rio de Janeiro, 2002.
} 
CHATFIELD, S. N.; DOUGAN, G. New generation vaccines. In: LEVINE, M. M. et al. 2.ed. Novel Vaccination Strategies. New York: Plenum Press, 1997. p. 331-341.

CHEN, H.; SCHIFFERLI, D. M. Mucosal and systemic immune responses to chimeric fimbriae expressed by Salmonella enterica serovar Typhimurium vaccine strains. Infect. Immun., v. 68, p. 3129-3139, 2000.

COOPER, C. R.; DAUGHERTY, A. J.; TACHDJIAN, S.; BLUM, P. H.; KELLY, R. M. Role of vapBC toxin-antitoxin loci in the thermal stress response of Sulfolobus solfataricus. Biochem. Soc. Trans., v. 37, n. 1, p. 123-126, 2009.

COORDENAÇÃO DE VIGILÂNCIA EM SAÚDE. 2005. Disponível em: <http://portal. prefeitura.sp.gov.br/secretarias/saude/vigilancia_saude /ccz/0067/>. Acesso em: 15 jan. 2008.

CORRÊA, J. R. Dinâmica das doenças infecciosas e parasitárias. Rio de Janeiro: Guanabara Koogan, 2005.

COYNAULT, C.; NOREL, F. Comparison of the abilities of Salmonella typhimurium rpoS, aroA and rpoS aroA strains to elicit humoral immune responses in BALB/c mice and to cause lethal infection in athymic BALB/c mice. Microbiol. Pathog., v. 26, n. 6, p. 299-305, 1999.

DAINES, D. A.; WU, M. H.; YUAN, S. Y. VapC-1 of Nontypeable Haemophilus influenzae Is a Ribonuclease. J. Bacteriol., v. 7, p. 5041-5048, 2007.

DEMPLE. B. Redox signaling and gene control in the Escherichia coli soxRS oxidative stress regulon. Gene, v. 179, n. 1, p. 53-57, 1996. Review.

FAINE, S.; ADLER, B.; BOLIN, C.; PEROLAT, P. Leptospira and leptospirosis. 2.ed. Melbourne: MedSci, 1999. 353 p.

FARR, W. Leptospirosis. Clin. Infect. Dis., v.21, p.1-8, 1994.

GAMBERINI, M.; GOMEZ, R. M.; ATZINGEN, M. V.; MARTINS, E. A. L.; VASCONCELLOS, S.; ROMERO, E. C., LEITE, L. C. C.; HO, P. L.; NASCIMENTO, A. L. T. O. Whole-genome analysis of Leptospira interrogans to identify potential vaccine candidates against leptospirosis. FEMS Microbiol. Lett., v. 244, p. 305-313, 2005.

GARMORY, H. S.; BROWN, K. A.; TITBALL, R. W. Salmonella vaccines for use in humans: present and future perspectives. Microbiol. Rev., v. 26, p. 339-353, 2002.

GERDES, K.; CHRISTENSEN S. K.; LOBNER-OLESEN, A. Prokaryotic toxinantitoxin stress response loci. Nat. Rev. Microbiol., v. 3, n. 5, p. 371-82, 2005.

HAYES, C. S. E SAUER, R. T. Toxin-antitoxin pairs in bacteria: killers or stress regulators? Cell, v. 10, n. 112, p. 2-4, 2003. 
HEINEMANN, M. B.; GARCIA, J. F.; NUNES, C. M.; GREGORI, F.; HIGA, Z. M. M.; VASCONCELLOS, S. A.; RICHTZENHAIN, L. J. Detection and differentiation of Leptospira spp. serovars in bovine semen by polymerase chain reaction and restriction fragment length polymorphism. Vet. Microbiol., v. 73, p. 261-267, 2000.

HOISETH, S. K.; STOCKER, B. A. Aromatic-dependent Salmonella typhimurium are non-virulent and effective as live vaccines. Nature, v. 5812, p. 238-239, 1981.

JANEWAY, C. A.; Travers, P. Immunobiology. 7.ed. Rio de Janeiro: Guanabara Koogan, 2002. $566 \mathrm{p}$.

JÖRG, L.; SPRINGER, S.; CHRISTOPH; WERNER, C. E.; LINDNER, T.; BELLMAN, N.;STRAUBINGER, R. K.; SELBITZ, H. J.; ALBER, G. Immunity induced with a Salmonella enterica serovar Enteritidis live vaccine is regulated by Th1-celldependent cellular and humoral effector mechanisms in susceptible BALB/c mice. Vaccine, v. 29, n. 22, p. 4779-93, 2006.

KATZ, M. E.; HOWARTH, P. M.; YONG, W. K., RIFFKIN, G. G.; DEPIAZZI, L. J.; $\mathrm{ROOD}, \mathrm{J}$. I. Identification of three gene regions associated with virulence in Dichelobacter nodosus, the causative agent of ovine footrot. J. Gen. Microbiol., v. 137, p. 2117-2124, 1991.

KO, A. I.; GALVÃO REIS, M.; RIBEIRO DOURADO, C. M.; JOHNSON, W. D. J, RILEY, L.W. Urban epidemic of severe leptospirosis in Brazil. Lancet, v. 354, p. 820825, 1999.

KOUTSOLIOUTSOU, A.; MARTINS, E. A.; WHITE, D. G.; LEVY, S. B.; DEMPLE, B. A soxRS-constitutive mutation contributing to antibiotic resistance in a clinical isolate of Salmonella enterica (Serovar typhimurium). Antimicrob. Agents Chemother., v. 45 , n. 1 , p. $38-43,2001$.

LAEMMLI, U. K. Cleavage of structural proteins during assembly of the head of bacteriophage T4. Nature, v. 227, p. 680-685, 1970.

LEE, S. H.; KIM, K. A.; PARK, Y. G.; SEONG I. W.; KIM, M. J.; LEE, Y. J. Identification and partial characteization of a novel hemolysin from Leptospira interrogans serovar lai. Gene, v. 254, p. 19-28, 2000.

LEVETT, P. N. Leptospirosis. Clin. Microbiol. Rev., v. 14, p. 296-326, 2001.

LEVETT, P. N. Usefulness of serologic analysis as a predictor of the infecting serovar in patients with severe leptospirosis. Clin. Infect. Dis., v.36, p. 447-452, 2003.

LOMAR, A. V.; DIAMENT, D.; TORRES, J. R. Leptospirosis in Latin America. Infect. Dis. Clin. North Am., v. 14, p. 23-39, vii-viii, 2000.

MAROTO, P. C. Outcome of leptospirosis in children. Am. J.Trop. Med. Hyg., v. 56, p. 307-310, 1997. 
MARTINEZ SANCHEZ, R.; OBREGON FUENTES, A. M.; PEREZ SIERRA, A.; BALY GIL, A.; DIAZ GONZALEZ, M.; BARO SUAREZ, M.; MENENDEZ CAPOTE, R.; RUIZ PEREZ, A.; SIERRA GONZALEZ G.; LOPEZ CHAVEZ, A. U. The reactogenicity and immunogenicity of the first Cuban vaccine against human leptospirosis. Rev. Cubana Med. Trop., v. 50, p. 159-166, 1998.

MIALLAU, L.; FALLER, M.; CHIANG, J.; ARBING, M.; GUO, F.; CASCIO, D. EISENBERG, D. Structure and proposed activity of a member of the VapBC family of toxin-antitoxin systems. VapBC-5 from Mycobacterium tuberculosis. J. Biol. Chem., v. 284, n. 1, p. 276-83, 2009.

MINISTÉRIO DA SAÚDE. Portal da Saúde. Disponível em: <http://200.214.130.38/portal/saude/visualizar_texto.cfm?idtxt=21740>. Acesso em: 14 fev. 2009.

MURRAY, P. M.; ROSENTHAL, K. S.; KOBAYASHI, G. S.; PFALLER, M. A. Treponena, Borrelia e Leptospira. In: MURRAY, Patrick R. Microbiologia Médica. 3. ed. Rio de Janeiro: Guanabara Koogan, 2000. p. 285-288.

NASCIMENTO, A. L.; KO, A. I.; MARTINS, E. A.; MONTEIRO-VITORELLO, C. B.; HO, P. L.; HAAKE, D. A.; VERJOVSKI-ALMEIDA, S.; HARSTKEERL, R. A; MARQUES, M. V.; OLIVEIRA, M. C.; MENCK, C. F. M.; LEITE, L. C. C. ; CARRER, H. ; COUTINHO, L. L.; DEGRAVE, W. M.; DELLAGOSTIN, O. A.; EL- DORRY, H.; FERRO, M.I.T.; FURLAN, L.R. ; GAMBERINI, M. ; GIGLIOTI,E.A. ; GOES-NETO, A.; GOLDMAN, G. H.; HARAKAVA, R.; JERONIMO, S. M. B.; JUNQUEIRA-DEAZEVEDO, I. L. M.; KIMURA, E. T.; KURAMAE, E. E.; LEMOS, E. G .M.; LEMOS, M. V .F.; MARINO, C. L.; NUNES, L. R.; OLIVEIRA, L.C.; PEREIRA G. G.; REIS, M. S.; SCHRIEFER, A.; SIQUEIRA, W. J.; SOMMER, P.; TSAI, S. M.; SIMPSON, A. J. G.; FERRO, J. A.; CAMARGO, L. E. A.; KITAJIMA, J. P.; SETUBAL, J. C.; VAN SLUYS, M. A. Comparative Genomics of two Leptospira interrogans serovars reveals novel insights into physioly and pathogenesis. J. Bacteriol., v. 186, n. 7, p. 2164-72, 2004.

NASCIMENTO, A. L.; VERJOVSKI-ALMEIDA, S.; VAN SLUYS, M. A.; MONTEIROVITORELLO, C. B.; CAMARGO, L. E.; DIGIAMPIETRI, L. A.; HARSTKEERL, R. A.; HO, P. L.; MARQUES, M. V.; OLIVEIRA, M. C.; SETUBAL, J. C.; HAAKE, D. A.; MARTINS, E. A. Genome features of Leptospira interrogans serovar Copenhageni. Braz. J. Med. Biol. Res., v. 37, p. 459-477, 2004.

NICODEMO, A. C.; DUARTE, M. I.; ALVES V. A.; TAKAKURA C. F.; SANTOS R. T.; NICODEMO, E. L. Lung lesions in human leptospirosis: microscopic, immunohistochemical, and ultrastructural features related to thrombocytopenia. Am. J. Trop. Med. Hyg., v., 56, p. 181-187, 1997.

PALANIAPPAN, R. U.; MCDONOUGH, S. P.; DIVERS, T. J.; CHEN, C. S.; PAN, M. J.; MATSUMOTO, M.; CHANG, Y. F. Immunoprotection of recombinant leptospiral immunoglobulin-like protein A against Leptospira interrogans serovar Pomona infection. Infect. Immun., v. 3, p. 1745-1750, 2006.

PANDEY, P.; GERDES, K. Toxin-antitoxin loci are highly abundant in free-living but lost from host-associated prokaryotes. Nucleic Acids Res., v. 33, n. 3, p. 966-976, 2005. 
PASETTI, M. F.; BARRY, E. M.; LOSONSKY, G.; SINGH, M.; MEDINA-MORENO, S. M.; POLO, J. M.; ULMER, J.; ROBINSON, H.; SZTEIN, M. B.; LEVINE, M. M. Attenuated Salmonella enterica serovar Typhi and Shigella flexneri 2 a strains mucosally deliver DNA vaccines encoding measles virus hemagglutinin, inducing specific immune responses and protection in cotton rats. J. Virol., v. 77, n. 9, p. 5209-17, 2003.

PICARDEAU, M.; BULACH, D. M.; BOUCHIER, C.; ZUERNER, R. L.; ZIDANE, N.; WILSON, P. J.; CRENO, S.; KUCZEK, E. S.; BOMMEZZADRI, S.; DAVIS, J. C.; MCGRATH, A.; JOHNSON, M. J.; BOURSAUX-EUDE, C.; SEEMANN, T.; ROUY, Z.; COPPEL, R. L.; ROOD ,J. I.; LAJUS, A.; DAVIES, J. K.; MÉDIGUE, C.; ADLER, B. Genome sequence of the saprophyte Leptospira biflexa provides insights into the evolution of Leptospira and the pathogenesis of leptospirosis. PLoS One, v. 13, n. 3, p. 1607, 2008.

PLANK, R.; DEAN, D. Overview of the epidemiology, microbiology, and pathogenesis of Leptospira ssp. in humans. Microbes Infect., v. 2, p. 1265-1276, 2000. Review.

QORONFLEH, M. W.; HESTERBERG, L. K.; SEEFELDT, M. B. Confronting highthroughput protein refolding using high pressure and solution screens. Protein Expr. Purif., v. 55, n. 2, p. 209-224, 2007.

RAMOS, C. R.; ABREU, P. A.; NASCIMENTO, A. L.; HO, P. L. A high-copy T7 Escherichia coli expression vector for the production of recombinant proteins with a minimal N-terminal His-tagged fusion peptide. Braz. J. Med. Biol. Res., v. 37, n. 8, p. 1103-1109, 2004.

Ren, S. X.; Fu, G.; Jiang, X. G.; Zeng, R.; Miao, Y. G.; Xu, H.; Zhang Y. X.; Xiong H.; Lu, G.; Lu, L. F.; Jiang, H. Q.; Jia, J.; Tu, Y. F.; Jiang, J. X.; Gu, W. Y.; Zhang, Y. Q.; Cai, Z.; Sheng, H. H.; Yin H. F.; Zhang, Y.; Zhu, G. F.; Wan, M.; Huang, H. L.; Qian, Z.; Wang, S. Y.; Ma, W.; Yao, Z. J.; Shen, Y.; Qiang, B. Q.; Xia, Q. C.; Guo, X. K.; Danchin, A.; Saint Girons, I.; Somerville, R. L.; Wen, Y. M.; Shi, M. H.; Chen, Z.; Xu, J. G. ; Zhao, G. P. Unique physiological and pathogenic features of Leptospira interrogans revealed by whole-genome sequencing. Nature, v. 24 , n. 422, p. 888-93, 2003.

RIBEIRO, A. F. Leptospirose, avaliação de fatores prognósticos da doença, município de São Paulo, 2005. Boletim Epidemiológico de São Paulo, ano 3, n. 28, abr., 2006.

ROSENKRANZ, C. D.; CHIARA, D.; AGORIO, C.; BAZ, A.; PASETTI, M. F.; SCHREIBER, F.; DEMATTEIS, S.; MARTINEZ, M.; SZTEIN, M. B.; CHABALGOITY, J. A. Towards new immunotherapies: targeting recombinant cytokines to the immune system using live attenuated Salmonella. Vaccine, v. 21, p. 798-801, 2003.

SAKATA, E. E.; YASUDA, P. H.; ROMERO, E. C.; SILVA, M. V.; LOMAR, A. V. Sorovares de $L$. interrogans isolados de casos de leptospirose humana em São Paulo, Brasil. Rev. Inst. Med. Trop., v. 34, p. 217-221, 1992. 
SBROGIO- ALMEIDA, M. E. E FERREIRA, L. C. S. Flagelin expressed by live Salmonella vaccine strains induces distinct antibody responses following delivery via systemic or mucosal imunization routes. Fems Immunol. Med. Microbiol., v. 30, p. 203-208, 2001.

SAMBROOK, J.; FRITSCH, E. F.; MANIATIS, T. Molecular Cloning: a laboratory manual. 2.ed. New York: Cold Spring Harbor Laboratory Press, 1989.

SÃO PAULO (Estado). Secretaria Estadual da Saúde. Centro de Vigilância Epidemiológica. Manual de Vigilância Epidemiológica - Leptospirose. São Paulo: CVE, 1994.

SILVA, E. F.; MEDEIROS, M. A.; MCBRIDE, A. J.; MATSUNAGA, J.; ESTEVES, G.S.,; RAMOS, J. G.; SANTOS, C. S.; CRODA, J., HOMMA, A., DELLAGOSTIN, O.A., HAAKE, D. A.; REIS, M. G.; KO, A. I. The terminal portion of leptospiral immunoglobulin- like protein LigA confers protective immunity against lethal infection in the hamster model of leptospirosis. Vaccine, v. 25, p. 6277-6286, 2007.

SIRARD, JEAN-CLAUDE; NIEDERGANG, FLORENCE; KRAEHENBUHL, JEANPIERRE Live attenuated Salmonella: a paradigm of mucosal vaccines, vaccines and vaccination. Part Immunol., v. 171, p. 5-26, 1999. Review.

TOMITA, E.Y. Construção de Linhagens recombinantes de salmonelas atenuadas a serem utilizadas como vetor vivo, expressando antígenos heterólogos para imunização via oral e nasal. Tese (Doutorado) - Universidade de São Paulo, Programa de Pós- Graduação Interunidades em Biotecnologia, São Paulo, 2005.

TRABULSI, L. R. Microbiologia. 4 ed. Rio de Janeiro: Atheneu, 1996. p. 212-213.

VERONESI R. Doenças infecciosas e parasitárias. 8 ed. Rio de Janeiro, Guanabara Koogan, 2004.

WANDERSMAN, C; STOJILJKOVIC I. Bacterial heme sources: the role of heme, hemoprotein receptors and hemophores. Curr. Opin. Microbiol., v. 3, n. 2, p. 21520, 2000. Review.

ZHANG,Y. X.; GUO, X. K.; WU, C.;BO B.I.; XI REN, S.; WU, C. F.; ZHAO, G. P. Characterization of a novel toxin-antitoxin module, VapBC, encoded by Leptospira interrogans chromosome. Cell Res., v. 14, n. 3, p. 208-216, 2004.

ZHANG, Y. X.; GENG, Y.; YANG, J. W.; GUO, X. K.; ZHAO, G. P. Cytotoxic activity and probable apoptotic effect of Sph2, a sphigomyelinase hemolysin from Leptospira interrogans strain Lai. BMB Rep., v. 41, n. 2, p. 119-125, 2008.

ZHUO, J. T; WANG, S. S.; LAN W. L. A discution on setting up target age group for imunization against leptospirosis. Zhonghua Liu Xing Bing Xue Za Zhi, v. 16, n. 4, p. 228-30, 1995. 